\title{
A (re)construção identitária de Juazeiro: as representações do jornal Correio do Cariry e $O$ Rebate na sua construção social
}

\author{
Edgard PATRÍCIO ${ }^{1}$ \\ Cícero Dantas QUEIROZ ${ }^{2}$
}

\begin{abstract}
Resumo:
O presente artigo contempla a construção e reconstrução da identidade do povoado de Juazeiro (CE), do início do século XX, vislumbrada por dois jornais impressos, Correio do Cariry, da cidade do Crato (CE), e $O$ Rebate, considerado o primeiro periódico de Juazeiro. A partir de uma reflexão teórica sobre a análise da influência das mídias na construção de sentidos, analisamos como o discurso jornalístico contribuiu no processo de constituição de novas representatividades de Juazeiro, no período em que o povoado buscou sua independência política da cidade do Crato. Para isso, são analisados conteúdos editoriais veiculados entre 1910 e 1911, que marcam o período de embate entre os semanários Correio do Cariry e O Rebate, pautado na disputa pela emancipação política do povoado.
\end{abstract}

Palavras-chave:

Jornal O Rebate. Jornal Correio do Cariry. Imprensa de Juazeiro.

\section{The identity (re)construction of Juazeiro: the representations of the newspaper Correio do Cariry and $\boldsymbol{O}$ Rebate in its social construction}

\begin{abstract}
:
The present article contemplates the construction and reconstruction of the identity of the town of Juazeiro (CE), from the beginning of the 20th century, glimpsed by two printed newspapers, Correio do Cariry, from the city of Crato (CE), and $O$ Rebate, considered the first periodical of Juazeiro. From a theoretical reflection on the analysis of the influence of the media in the construction of meanings, we analyze how journalistic discourse contributed in the process of constitution of new representations of Juazeiro, in the period in which the town sought its political independence from the city of Crato. To do so, editorial content published between 1910 and 1911 is analyzed, marking the period of clash between the weekly Correio do Cariry and $O$ Rebate, based on the dispute for the political emancipation of the town.

Keywords:

O Rebate Journal; Correio do Cariry Journal; Press of Juazeiro.

\section{A (re)construcción identitaria de Juazeiro: las representaciones de los periódicos Correio do Cariry y El Rebate en su construcción social}

Resumen:

El presente artículo contempla la construcción y reconstrucción de la identidad del pueblo de Juazeiro (CE), de principios del siglo XX, vislumbrada por dos periódicos impresos, Correio do Cariry, de la ciudad de Crato (CE); y El Rebate, considerado el primer periódico de Juazeiro. A partir de una reflexión teórica sobre el análisis de la influencia de los medios en la construcción de sentidos, analizamos cómo el discurso periodístico contribuyó en el proceso de constitución de nuevas representaciones de Juazeiro, en el período en que el pueblo buscó su independencia política de la ciudad del Crato. Para ello, se analizan contenidos editoriales vehiculados entre 1910 y 1911, que marcan el período de embate entre los semanarios Correio do Cariry y $O$ Rebate, pautado en la disputa por la emancipación política del pueblo.

\footnotetext{
${ }^{1}$ Jornalista. Professor do Curso de Jornalismo e do Programa de Pós-graduação em Comunicação da Universidade Federal do Ceará. Coordenador do Grupo de Pesquisa PraxisJor - Práxis no Jornalismo. Email: edgard@ufc.br

2 Jornalista. Mestrando do Programa de Pós-graduação em Comunicação da Universidade Federal do Ceará. E-mail: cicerodantasjornalismo@gmail.com
}

ISSN: 2238-5126 
Palabras clave:

Diario El Rebate; Diario Correio do Cariry; Prensa de Juazeiro.

\section{INTRODUÇÃO}

O município de Juazeiro do Norte surgiu no vale do Cariri, localizado ao sul do Estado do Ceará. Cercada pela Chapada do Araripe, a região é contemplada por uma rica vegetação, terras férteis e por mais de cem fontes de água perene. Graças a esses recursos naturais, o Cariri passou a ser considerado um verdadeiro oásis encravado no sertão nordestino, tornando-se atrativo de retirantes sertanejos a partir do século XVIII.

Ainda nesse século, o Crato adquiriu o status de maior centro econômico e populacional do vale do Cariri e do interior do Ceará. Tornou-se o principal produtor e exportador de alimentos para o sertão árido brasileiro. Transformou-se em importante centro de distribuição de manufaturas europeias importadas e no maior centro comercial e populacional do Estado, atrás apenas da capital Fortaleza (DELLA CAVA, 1976).

O povoado onde hoje se localiza a cidade de Juazeiro do Norte era denominado de fazenda Tabuleiro Grande, localizado no Engenho Moquém, município de Crato. A partir de 1827, com o início da construção da capela dedicada à Nossa Senhora das Dores, projetada pelo sacerdote, recém-ordenado, padre Pedro Ribeiro de Carvalho, a aldeia foi crescendo, aumentando o número de casas localizadas sempre em torno da igrejinha (OLIVEIRA, 1989).

Construída a capela de Nossa Senhora das Dores, padre Pedro Ribeiro se tornou o primeiro capelão e ocupou o cargo até 1856, ano de seu falecimento. Entre 1856 e 1871 , a capela receberia mais quatro sacerdotes ${ }^{3}$. A partir de 1872 , com a chegada do padre Cícero Romão Batista ${ }^{4}$, o pacato povoado ganharia uma nova configuração social e política.

Padre Cícero fixou residência em Juazeiro após ordens do bispo do Ceará, Dom Luiz, que o nomeou como novo capelão da igrejinha de Nossa Senhora das Dores, em setembro de 1872. Dezessete anos após ser nomeado capelão, padre Cícero protagonizou um fato que mudaria para sempre sua vida sacerdotal e da pequena vila. $\mathrm{Na}$ primeira sexta-feira da quaresma, março de 1889 , após uma exaustiva noite de

\footnotetext{
${ }^{3}$ O segundo capelão foi padre Luiz Barbosa; o terceiro seria o padre Antonio Almeida; o quarto, padre Joaquim Coêlho e o quinto foi o padre Pedro Ferreira de Melo (OLIVEIRA, 1989).

${ }^{4}$ Cícero ordenou-se aos 26 anos, em 30 de novembro de 1870 . Retornou ao Crato em $1^{\circ}$ de janeiro de 1871, onde rezou sua primeira missa. No natal do mesmo ano, foi convidado pelo professor Simeão Correia Macedo para celebrar a missa de Natal na capela de Nossa Senhora das Dores, em Juazeiro, que no momento estava sem capelão.
} 
orações e penitências com os associados do Apostolado da Oração ${ }^{5}$ na capela de Nossa Senhora das Dores, o sacerdote decidiu encerrar a vigília ministrando a comunhão da Sagrada Eucaristia às pessoas que lá estavam. Uma delas era a Beata Maria de Araújo ${ }^{6}$ :

[...] uma das primeiras a receber a Comunhão. De repente, caiu por terra e a Imaculada Hóstia branca que acabava de receber tingiu-se de sangue. $\mathrm{O}$ fato extraordinário repetiu-se todas as quartas-feiras e sextas-feiras da Quaresma, durante dois meses; do domingo da Paixão até o dia de festa de Ascensão do Senhor, por 47 dias, voltou a ocorrer diariamente. (DELLA CAVA, 1976, p. 45).

O sangramento da hóstia na boca de Maria de Araújo é a hierofania manifestação do sagrado - que fundou Juazeiro como espaço sagrado. O fenômeno dito milagroso deixou os populares em êxtase. A notícia se espalhou rapidamente e moradores de localidades próximas chegaram de forma espontânea ao povoado. Teve início a mística religiosa em torno de Juazeiro, cujos efeitos ainda são sentidos atualmente, com as romarias ${ }^{7}$ realizadas na cidade.

A ocorrência do sangramento da hóstia está no cerne da formulação do que chamamos de história oficial de Juazeiro, fundada oficialmente em 22 de junho de 1911. No entanto, é necessário ressaltar que em nosso trabalho a cidade de Juazeiro não existe. Em seu lugar, um pequeno povoado que possuía pouco mais de dois mil habitantes em 1889 se encontrava dentro dos limites e, portanto, sob jurisdição civil e religiosa da cidade do Crato, distante 580 quilômetros da capital Fortaleza.

É a partir da transubstanciação da eucaristia, segundo Della Cava (1976), que tem início a rivalidade entre o povoado de Juazeiro e a cidade do Crato. Após o dito milagre, Juazeiro foi alvo de rápida expansão demográfica ${ }^{8}$, fato que influenciou positivamente a economia ${ }^{9}$ local. Os novos moradores passaram a trabalhar no campo, nos engenhos e nas indústrias artesanais. A pequena vila estava ganhando vida própria e

\footnotetext{
${ }^{5}$ Apostolado da Oração, uma associação leiga que nasceu na França em 1844 e foi aprovada pelo papa Pio IX em 1849, também conhecida como Associação do Sagrado Coração de Jesus. A primeira sessão do Apostolado da Oração na região do Cariri foi inaugurada na capela do Juazeiro em 1888 (NOBRE, 2010). ${ }^{6}$ Maria de Araújo nasceu em 24 de março de 1862, era costureira por profissão e, segundo ela, beata por inspiração divina, já que, desde os oito anos, ao fazer sua primeira comunhão, consagrou-se como "verdadeira esposa de Cristo" (NOBRE, 2010).

7 Atualmente a cidade conta com três grandes romarias. O Chamado "ciclo de romaria" inicia-se em setembro com a festa de Nossa Senhora das Dores; em novembro ocorre a romaria de finados; fechando o ciclo em janeiro, com a romaria de Nossa Senhora das Candeias. Durante todo o ano, em datas efêmeras, Juazeiro recebe outras romarias, como acontece na data do falecimento do padre Cícero, em 20 de julho.

${ }^{8}$ Entre 1890 e 1898, a população de Juazeiro mais que duplicou, ultrapassando 5 mil habitantes; em 1905, subiu para 12 mil; em 1909, chegou a 15 mil (DELLA CAVA, 1976).

9 Juazeiro lucrou com a chegada dos romeiros do Padre Cícero, adquirindo quase sua independência econômica, apenas com as plantações agrícolas (OLIVEIRA, 1989).
} 
sua população começou a ambicionar a independência. Do outro lado, a cidade do Crato sentiu sua hegemonia ameaçada e se opôs ao desejo de emancipação dos juazeirenses. A cidade não abriria mão da boa fonte de impostos proveniente de Juazeiro.

O suposto milagre provocou, também, a perseguição da Igreja Católica, representada pela Diocese do Ceará, contra o padre Cícero e aos "fanáticos de Juazeiro", termo então utilizado pelo clero cratense e cearense para se referirem aos devotos. Os clérigos cratenses renegaram veementemente os fenômenos e comportamentos presenciados no povoado vizinho, rotulando-os como seita cancerosa política e religiosa. Para não ter sua imagem vinculada aos "fanáticos", os cratenses passaram, a partir de então, a erguer uma imagem de cidade civilizada e de cultura letrada (CORTEZ, 2000).

Por sua vez, os habitantes de Juazeiro passaram a boicotar os padres e as missões evangélicas do Crato, o que provocou uma verdadeira rixa entre os fiéis do padre Cícero e a Igreja Católica oficial cratense. Fato, este, que chegou a gerar uma ameaça de revolta camponesa no vale do Cariri (DELLA CAVA, 1976).

A velha animosidade entre os dois povos, iniciada em 1889, ressurgiria com mais força em 1909, quando o povoado de Juazeiro oficializou seu pedido de autonomia municipal. A rivalidade, agora pautada pelo pedido de independência, ganhou os jornais impressos das duas localidades. O Rebate, primeiro periódico do povoado de Juazeiro, fundado em 1909, pelo padre Joaquim de Alencar Peixoto, se firmou como importante instrumento na empreitada juazeirense. O Correio do Cariry, semanário do Partido Republicano Cratense, fundado por Antônio Luiz Alves Pequeno, intendente do Crato, em 1904, defenderia os anseios das autoridades locais. O embate entre as duas localidades não envolveria armas e exércitos, mas, sim, ideias, formas, imagens e representações.

\section{Identidades: processo, construção e invenção}

Os produtos jornalísticos constituem material profícuo para a interpretação da vida social de uma época, fornecendo mapas das crenças e dos consensos constituídos historicamente (HALL, 1999, p. 226). Consideramos o jornal como um espaço privilegiado para a construção de memórias, de identidades e de representações sociais capazes de gerar e fixar representações acerca de fatos, pessoas, espaços e datas. Na era moderna, os meios de comunicação de massa deram nova dimensão ao fluxo discursivo, 
o que contribuiu para a ampliação e aceleração das trocas simbólicas por meio de diferentes canais e linguagens.

Ressaltamos que o presente artigo pretende identificar como dois veículos de comunicação representaram o povoado de Juazeiro, quando este buscou sua emancipação política. Correio do Cariry,contrário, passou a construir uma imagem negativa do povoado, para deslegitimar suas pretensões políticas, e $O$ Rebate, favorável, enaltecia as conquistas econômicas de Juazeiro, justificando sua campanha pela independência. Portanto, buscamos compreender e desvendar como essas identidades foram produzidas/inventadas e ativadas/reivindicadas, por esses veículos de comunicação.

De acordo com Stuart Hall (2007), as discussões sobre a questão da identidade são complexas. O próprio conceito tem sido submetido a severas críticas, por suas ambiguidades teóricas e políticas. Para o autor, só é possível estudar sobre a temática a partir de uma rasura. "A identidade é um desses conceitos que operam 'sob rasura', no intervalo entre a inversão e a emergência: uma ideia que não pode ser pensada da forma antiga, mas sem a qual certas questões-chave não podem ser sequer pensadas" (HALL, 2007, p. 104). Portanto, a identidade não pode ser entendida como relacionada apenas ao Estado-Nação, pois esta relação é muito restrita ao potencial de compreensão nos estudos culturais e políticos.

Segundo Woodward (2007), as identidades são fabricadas por meio da marcação da diferença. Essa marcação ocorre tanto por meio de sistemas simbólicos de representação, quanto por meio de formas de exclusão social. No caso estudado, a ação principal que dividiu as duas localidades foi o simbolismo religioso arraigado em Juazeiro e renegado pela alta sociedade cratense. Foi a partir dessa diferença cultural que se constituíram as representações imagéticas das duas localidades, aplicando um "princípio de diferença a uma população de uma forma tal que seja capaz de dividi-la (a todas as suas características) em ao menos dois grupos opostos - nós/eles" (WOODWARD, 2007, p. 40).

Para Bhabha (1998), as identidades são fixadas, parcialmente, por meio da diferença, em um processo deslizante de significados e posições de sujeito. Nesse caso, a identidade é um processo problemático de acesso a uma imagem da totalidade. Por meio das condições discursivas, essa imagem é construída como representação, sendo a marca de uma diferença, mas também lugar de uma ambivalência, uma vez que sua 
representação é “espacialmente fendida - ela torna presente algo que está ausente - e temporalmente adiada: é a representação de um tempo que está sempre em outro lugar, uma repetição" (BHABHA, 1998, p. 85).

Dessa forma, as reivindicações de identidade são nominativas e normativas, em um dado momento, que é preliminar e passageiro. As identidades não são produções historicamente progressivas com os mesmos conteúdos; mudam seus discursos através do tempo e no espaço de acordo com a situação e interesse. Portanto, "as formas de identidade social devem ser capazes de surgir dentro-e-como a diferença de um-outro e fazer do direito de significar um ato de tradução cultural" (BHABHA, 1998, p. 322).

Damatta (2004) afirma que a construção das identidades implica relações. Para o autor, "qualquer identidade, mesmo aquelas que se definem como 'individuais', realizase por referências internas e externas, por meio de comparações com outras comunidades que se situam no seu âmbito histórico-social" (DAMATTA, 2004, p. 20). Citando o antropólogo francês Louis Dumont, o autor completa: "Uma cultura jamais existe em isolamento, mas deve ser vista em relação ao seu ambiente" (DAMATTA, 2004, p. 20). Dessa forma, as identidades, internas ou externas, são buriladas, acentuadas, negadas, construídas ou inibidas em situações de contato que agenciam a comparação e a reflexibilidade.

A identidade, tal como a diferença, também é uma relação social. Isso significa que sua definição, discursiva e linguística, está sujeita a vetores de força e relações de poder. Ou seja, eles não são definidos, mas, sim, impostos. O processo de produção da identidade oscila entre dois momentos: de um lado, aqueles processos que tendem a fixar e estabilizar a identidade; de outro, os processos que tendem a subvertê-los e desestabilizá-los (SILVA, 2007). Caso, este, que vai ao encontro do embate presenciado nos jornais impressos de Crato e Juazeiro. Enquanto O Rebate buscou fixar uma nova representatividade do povoado de Juazeiro, focado na pujança econômica, o Correio do Cariry buscou desestabilizar o povoado rememorando a imagem negativa construída após os fenômenos religiosos, outrora conhecido como terra de retirantes fanáticos.

Para Hall (2003, p. 30), a identidade é irrevogavelmente uma questão histórica. Para o autor, as sociedades são compostas não de um, mas de muitos povos. Aqueles sujeitos que estão em um lugar hoje, pertenciam, originalmente, a outro. Por isso, longe de constituir uma continuidade com o nosso passado, nossa relação com a história é marcada pelas rupturas, pelos silêncios, que são, muitas vezes, violentos e abruptos. 
Ainda para Hall (2007), as identidades parecem invocar, para suas práticas discursivas, uma origem que residiria em um passado histórico com o qual elas mantêm certa correspondência. $\mathrm{O}$ autor acena que as identidades utilizam-se dos "recursos da história, da linguagem e da cultura para a produção não daquilo que nós somos, mas daquilo no qual nos tornamos" (HALL, 2007, p. 109). Por isso, as identidades relacionam-se não tanto com as questões "quem nós somos?" ou "de onde nós viemos?", mas, muito mais com as questões "quem nós podemos nos tomar?", "como nós temos sido representados?" e "como essa representação afeta a forma como nós podemos representar a nós próprios?” (HALL, 2007, p. 109).

As identidades, portanto, surgem da narrativação do "eu", mas que não diminui sua eficácia discursiva, material ou política. Mesmo que essas identidades sejam, em parte, construídas pelo imaginário e/ou na fantasia, elas terão êxito na relação de pertencimento. Dessa forma, o discurso toma centralidade importante para a produção das identidades, e, por isso, "precisamos compreendê-las como produzidas em locais históricos e institucionais específicos, no interior de formações e práticas discursivas específicas, por estratégias e iniciativas especificas" (HALL, 2007, p. 109).

As identidades são construções históricas dos significados sociais e culturais que referenciam o processo de distinção e identificação do Outro. Nesse caso, são estabelecidas culturalmente e organizadas em torno de um conjunto de valores, cujo significado de uso compartilhado é marcado "por códigos específicos de autoidentificação: a comunidade de fiéis, os ícones de nacionalismo, a geografia local" (CASTELLS, 1999, p. 84). Portanto, as identidades são constituídas discursivamente, em torno de reações e projetos determinados por fatores históricos e geográficos.

Assim, a construção identitária é uma constante disputa pelo poder, como aponta Bauman (2005). É uma luta, uma guerra discursiva e legitimadora de um consenso, de uma "naturalização" das relações. As identidades são construídas no interior das relações de poder, nas disputas, nos campos de força entre a legitimação e a não legitimação, entre a identidade hegemônica e a identidade subalterna, num jogo de anunciação e aceitação da "verdade" historicamente construída. É isso que veremos a seguir nos discursos dos órgãos jornalísticos de Crato e Juazeiro, durante a discussão em torno da independência do distrito de Juazeiro.

\section{A (re)construção imagética de Juazeiro}


A partir da questão religiosa de 1889 , o povoado de Juazeiro ganhou uma nova configuração social. O pequeno distrito passou por um crescimento econômico e populacional repentino, graças aos milhares de peregrinos que se instalaram no local. $\mathrm{O}$ comércio tomou grande impulso com o aumento da produção, e as feiras passaram a ser bem frequentadas. Juazeiro crescia e sua população começou a acalentar a ideia de independência.

Em 1907 o movimento pró-autonomia de Juazeiro ganhou forma. Em agosto daquele ano, o major Joaquim Bezerra de Menezes, fazendeiro e descendente da família fundadora de Juazeiro, convocou os moradores para uma reunião, divulgada por meio de um boletim impresso. O objetivo era discutir a questão da autonomia política do distrito. Intitulado de "Ao povo do Joaseiro" o boletim instigou a população:

É chegado o momento de pugnarmos com alta energia e valor pela nossa elevação social, elevando Juazeiro à categoria de Município, aumentando assim a importância de toda zona do Cariri que bem merece os vossos serviços para chegar ao grau de prosperidade de que é digno. Tenhamos confiança no futuro e podemos aguardar os louros de uma esplendente vitória. (OLIVEIRA, 1989, p. 145).

O chamado de Joaquim Bezerra não rendeu o efeito esperado. A reunião foi um fiasco. A princípio não houve apoio popular, devido a divergências ideológicas ${ }^{10}$. O fracasso da reunião pode ser explicado também pela ausência do padre Cícero, que apoiou a campanha posteriormente. Em 1909, a campanha de emancipação de Juazeiro ganhou força com a fundação do primeiro jornal impresso do povoado, O Rebate.

Frequentemente, em processos de emancipação, o município que tem uma de suas regiões emancipadas posiciona-se contra esse projeto. Nesse caso, o Crato assumiu esse papel. O jornal Correio do Cariry tomou para si a função de representar a crítica às pretensões de Juazeiro. Em seu discurso, o povoado é caracterizado de forma depreciativa, considerado "foco das mais reprováveis irregularidades, [...] uma nodoa negra a manchar o céu da civilização brasileira, um teatro de vis explorações, cuja peça exclusiva levada quotidianamente em scena para illaquear a boa fé dos incantos" (JUAZEIRO..., 01 jan. 1911, p. 1).

Juazeiro e sua população passam a ser apresentados pelo Correio do Cariry de forma detratante, e, com bases nos aspectos sociais e culturais, justificava que aquele

\footnotetext{
${ }^{10}$ Os habitantes do povoado haviam se dividido entre dois grupos: os filhos da terra ou nativos, nascidos em Juazeiro; e adventícios, romeiros que ali fixaram moradia. Os adventícios, maioria da população, não aderiram à campanha por se considerarem discriminados pela população nativa. Logo, os chamados adventícios não aderiram ao pedido do coronel "nativo". Apenas com a participação do padre Cicero na campanha, a partir de 1907, os romeiros passaram a apoiar a emancipação do distrito.
} 
distrito não estava apto para conquistar sua autonomia político-administrativa. Como estratégia para barrar as pretensões do distrito vizinho, os redatores do semanário cratense resgataram a imagem de comunidade fanática originária após o dito milagre da hóstia. Classificaram o distrito como uma "pocilga asquerosa, tapera, logarejo retrogrado, corjas de bandidos, assassinos e desordeiros, uma especie de Sodoma ou Gomorra, terra classica dos preguiçosos” (INFAMES..., 12 jun. 1910, p. 1).

As identidades, como as narrativas, são construções discursivas e servem para enaltecer determinado contexto e relação e encobrir outras relações e contextos. Ou seja, a identidade se faz num jogo relacional "entre o que deve ser necessariamente lembrado e o que deve ser necessariamente esquecido em certas situações" (DAMATTA, 2004, p. 24). Logo, os articulistas cratenses, ao verem a hegemonia regional da cidade ameaçada, buscaram reviver uma Juazeiro de fanatismo fervoroso, de impostores e embusteiros, para deslegitimar a campanha pela emancipação política do povoado, uma vez que o distrito, economicamente, já se considerava apto para conquistar a autonomia.

Os redatores do Correio do Cariryobjetivaram desmoralizar o povoado vizinho perante a região do Cariri, do Estado do Ceará e nacionalmente. Criar uma rejeição geral à causa juazeirense facilitaria desarticular de uma vez por todas sua campanha pela emancipação. Dessa forma, telegrafar para outros jornais, comunicando sobre os fatos ocorridos em Juazeiro, foi uma das estratégias do órgão cratense. Periódicos da Bahia, do Rio de Janeiro, Pernambuco e do próprio Ceará chegaram a publicar notícias desmoralizantes sobre o povoado. Destacamos, aqui, o papel do telégrafo na empreitada do órgão cratense. Anteriormente, para transportar uma informação era necessário também transportar o meio de comunicação (impresso, manuscrito, etc.). O advento do sistema de telégrafos, durante a modernização da imprensa brasileira, permitiu que as mensagens fossem transportadas sem a dependência de mensageiros (BARBOSA, 2013).

A cada artigo publicado em outros impressos, descrevendo negativamente Juazeiro, os redatores cratenses republicavam-nos no Correio do Cariry. Um exemplo foi o artigo Os Milagres do Joaseiro, escrito pelo bispo de Olinda Dom Luiz Brito, direcionado aos vigários de sua diocese. O diocesano criticou as romarias realizadas pelos fiéis pernambucanos a Juazeiro e o padre Cícero por incitar as romarias no povoado: "[...] padre Cícero, que devia ser o primeiro a lhes ensinar como se acham em erro, dando assim prova de sua obdiencia á S. Congregação que condemnou seu desvio" 
(MILAGRES..., 06 nov. 1910, p. 1). Recomendou aos padres do interior de Pernambuco que aconselhassem os católicos da região a não realizarem mais romarias a Juazeiro considerado pelo bispo e pelos redatores cratenses, uma terra de embuste - e não batizassem cristãos com o nome de Cícero, considerado pelo diocesano "signal de arraigado fanatismo" (MILAGRES..., 06 nov. 1910, p. 1).

$\mathrm{O}$ imaginário do terror foi fartamente manipulado pela elite política cratense em busca de legitimidade nas suas pretensões de manter Juazeiro na dependência administrativa do Crato (CORTEZ, 2000). Além disso, tornou-se comum a detratação do Juazeiro e dos juazeirenses pelos redatores cratenses: "Sacerdotes de maus costumes, perversos, trampolineiros, simoníacos, cachaceiros, jogadores, pedophilos, onanistas, defloradores, amasiados à Liçon etc" (CORREIO DO CARIRY, 11 dez. 1910, p. 2), são alguns dos adjetivos negativos direcionados aos juazeirenses naquele jornal. Em suma, para o semanário cratense:

Juazeiro trabalha inegavelmente para acentuar dia-a-dia o fôro de uma
segunda Sodoma. Como a velha cidade da Palestina que as lavas do
céu enguliram pelas torpezas, iniquidades, corrupção e desregramento
de uns habitantes, a villa do Sr. Cícero, caminhando pari-passu para o
mesmo fim [...]. Não é de hoje nem de hontem a somma incalculável
dos crimes de que scenario aquella terra, appellidada - terra santa -
para mais facilmente engodar a boa fé dos homens que a olhavam com
um latibulo de fanático, nunca como um velhacouto de bandidos. [...].
E assim há muito que a mystica ciceropolis, equipara-se a Sodoma,
tendo ultrapassado os limites de uma Gomorra que não esteve sempre
muito aquém de sua irmã de castigo. (NOVA..., 02 fev. 1911, p. 1).

Estrategicamente, o Correio do Cariry buscou desconstruir a ideia de progresso de Juazeiro, mostrando-a como uma sociedade atrasada. Utilizou-se da lenda judaica das cidades de Sodoma e Gamorra para criar um efeito psicológico desmoralizador, desarticulador e até amedrontador para a região. Apresentou a população de Juazeiro ao mesmo tempo como mau, preguiçosa e retardada, não lhe sendo reservado adjetivo que a qualificasse positivamente, sendo negado o direito de ser e possuir algum traço positivo em sua personalidade. Sendo assim, os articulistas do Correio do Cariry sustentavam a tese de que Juazeiro iria por "água abaixo" sem a tutela do Crato.

Do outro lado, os juazeirenses buscaram estratégias para contrapor o jornal cratense. A imagem de comunidade fanática, rememorada pelo Correio do Cariry, seria contestada pelos moradores do povoado. A utilização do jornal $O$ Rebate foi de suma importância para auxiliar aquela população. Levando em consideração os conceitos de 
Spivak (2010), acreditamos ser $O$ Rebate um veículo que deu voz aquela população que almejava sua "liberdade". A autora afirma que o papel dos intelectuais não deve ser o de representar ou falar pelo sujeito subalterno, e, sim, abrir espaços para que ele possa falar e, mais do que isso, que possa ser ouvido. Ou seja, era necessário encontrar meios eficazes para que a população de Juazeiro fosse ouvida e se autorrepresentasse. E foi $O$ Rebate o meio encontrado por aquela população. Ao mesmo tempo em que a folha divulgava a campanha pela emancipação do povoado, permitiu, também, à população local manifestar suas inquietações.

$O$ Rebate publicou artigos e manifestos assinados pela população local. Em um dos protestos divulgados pela folha, os moradores criticaram as autoridades cratenses e os "ataques escritos" dirigidos à sua terra. Protesto esse, assinado por 923 moradores ${ }^{11}$. "É um protesto nobre e altivo expontaneamente por nós feito e de real importância, porque, alem de ser d'uma população inteira, não poderá, nem será contra-protestado por nenhuma outra localidade[...]" (PROTESTO, 08 jan. 1911, p.3). O manifesto juazeirense surtiu efeito e ganhou o apoio de municípios vizinhos, como Missão Velha e Milagres, que manifestaram apoio à causa.

Para justificar e legitimar a pretensão dos juazeirenses pela independência, os editores de $O$ Rebate baseavam-se no crescimento demográfico e econômico do povoado.

\begin{abstract}
Não é de hoje que o povo desta terra deseja a sua liberdade, a sua independencia, a sua emancipação política. [...] o Joaseiro é uma localidade que se ostenta, com justa ufania, laboratório de grande atividade. A sua febre de construção parece uma alucinação: trabalhase actualmente em mais de cincoenta prédios. [...] A sua indústria manufactureira, ou fabril desenvolve-se, como não em parte alguma nestes centros. A sua lavoura alarga-se admiravelmente [...] E, de par com toda essa evolução material, a sua evolução intelectual e moral: multiplicam-se escolas particulares que já se elevam à quarenta $\mathrm{e}$ cinco. [...] O Joaseiro vive! (ARDENTE..., 10 jun. 1910, p. 1).
\end{abstract}

Como estratégia de buscar apoio dos juazeirenses para a causa, os redatores de $O$ Rebate instigaram ainda o orgulho e a autoestima da população que vinha sendo ferida pelos cratenses, principalmente com a ideia de pujança econômica. O semanário apontou o distrito como o principal responsável pelo pagamento de impostos e, inversamente, o que menos recebia investimentos do Crato, que passou a ser apontado como o sanguessuga dos bens de Juazeiro:

\footnotetext{
${ }^{11}$ Ver jornal O Rebate 08, 22, 29 de janeiro e 05 e 12 de fevereiro de 1911.
} 
Por que conservar ainda o Juaseiro, quase duas vezes maior do que a cidade do Crato, que é considerada a primeira nestes sertões tórridos de 4 ou cinco estados vizinhos, dando ao fisco um rendimento superior ao desta, na sombra do desprezo com alcunha de povoação? Triste antagonismo da sorte! (...) É porque o Crato é o polvo que vai haurindo a seiva do Joaseiro (JOASEIRO, 29 maio 1910, p. 1).

Por duas vezes, o distrito de Juazeiro teve seu pedido de independência negado por Antônio Luiz. A negativa do coronel provocou manifesto da população juazeirense que se declarou independente, mesmo sem o aval do governo municipal e estadual, em ato organizado por $O$ Rebate, em agosto de 1910. Após a independência não oficial do povoado, a ameaça da batalha impressa se transformar em ataque armado perdurou por meses e preocupou importantes comerciantes cratenses.

Em 18 de fevereiro de 1911, os coronéis Abdon da Franca Alencar, presidente da Câmara do Crato, e os comerciantes Francisco de Britto, Diógenes Frazão e Pedro Gomes de Mattos se dirigiram a Juazeiro para tratarem de um acordo de paz. A comitiva cratense foi recebida pelo padre Cícero, padre Alencar Peixoto e o comerciante José André de Figueiredo. Na conferência ficou decidido: O Crato não iria mais se opor a emancipação política de Juazeiro, caso o povoado pagasse os impostos atrasados à Câmara cratense e a guerra editorial entre Correio do Cariry e $O$ Rebate cessasse.

\section{Considerações finais}

Na sociedade contemporânea a dimensão simbólica do Outro é recoberta pelo imaginário produzido pela indústria do espetáculo. A mídia atua de maneira central no processo de percepção da realidade e na construção de sentido. Nesse caso, tanto o Correio do Cariry, quanto $O$ Rebate construíram uma representação imagética do povoado de Juazeiro a partir de suas ideologias e objetivos de seus superiores.

Tomando como base os conceitos de Woodward (2007) e Bhabha (1998) consideramos o sangramento da hóstia de 1889 , ocorrido no povoado de Juazeiro, o marco fundante da diferença entre cratenses e juazeirenses. Nesse caso, a eclosão do fenômeno de Juazeiro em torno da figura do padre Cícero e as questões sócio-religiosas e políticas que se seguiram, alimentaram a lógica de contraste entre duas localidades vizinhas - Crato e Juazeiro - atribuindo-se à primeira o foro da civilidade e à segunda $\mathrm{o}$ foro da barbárie. Ao presenciar a construção da dita comunidade fanática em um dos seus distritos, fizeram surgir na intelectualidade cratense, pautada nos cânones da civilização e do cientificismo, um imaginário de terror acerca de Juazeiro. 
É a partir da negação ao fanatismo imputado aos moradores de Juazeiro que foi erguida a imagem civilizada e culta dos cratenses, e, consequentemente, as disputas entre as duas cidades durante todo o século XX. Já que Juazeiro, ao presenciar seu poderio econômico, iniciou uma disputa com os cratenses, não apenas pela sua independência, mas, também, pela desconstrução imagética criada pelo Outro (Crato), atribuída durante anos à vila de Juazeiro como uma terra de fanáticos, supersticiosos, atrasados, incivis, delinquentes e criminosos.

Nesse caso, os jornais impressos estudados foram catalisadores na construção identitária do povoado de Juazeiro. Expuseram a ideologia de seus superiores e protagonizaram um embate que foi muito além do cunho político. A imagem social e política criada pelo Correio do Cariry e $O$ Rebate ao distrito de Juazeiro representou uma constante disputa pelo poder, como apontado por Bauman (2005). Um embate discursivo entre a identidade hegemônica, dita culta, e a subalterna, dita fanática, que apresentaram uma Juazeiro por olhares distintos. Olhares, estes, que perduraram por décadas e ainda hoje permanecem na centenária Juazeiro do Norte, onde a fé/religião e trabalho/desenvolvimento urbano constituem sua identidade.

Submetido em: 30.11 .2016

Aceito em: 13.04.2017

\section{REFERÊNCIA BIBLIOGRÁFICA}

BARBOSA, Marialva. História da Comunicação no Brasil. Petrópolis: Vozes, 2013.

BAUMAM, Zygmunt. Identidade. Rio de Janeiro: Jorge Zahar, 2005.

BHABHA, Homi K. O local da cultura. Belo Horizonte: Ed. UFMG, 1998.

CASTELLS, Manuel. O poder da identidade. 3. ed. São Paulo: Paz e Terra, 1999.

CORTEZ, Antonia Otonite de Oliveira. A construção da "cidade da cultura": Crato (1889-1960). 2000. 211 f. Dissertação (Mestrado em História Social) - Universidade Federal do Rio de Janeiro, Rio de Janeiro, 2000.

DAMATTA, Roberto. Nação e região: em torno do significado cultural de uma permanente dualidade brasileira. SCHÜLER, Fernando Luís; BORDINI, Maria da Gloria (Org.). Cultura e identidade regional. Porto Alegre: EDIPUCRS, 2004, p. 1930 .

DELLA CAVA, Ralph. Milagre em Joaseiro. 2 ed. Rio de Janeiro: Paz e Terra, 1976. 
HALL, Stuart. A produção social das notícias: o mugging nos media. In: TRAQUINA, Nelson (Org.) Jornalismo: questões, teorias e "estórias". Lisboa: Vega, 1999, p. 224248.

Da diáspora: identidades e mediações culturais. SOVIK, Liv (Org.). Belo Horizonte: UFMG; Brasília: Representação da UNESCO no Brasil, 2003.

Quem precisa da identidade? In: SILVA, Tomaz Tadeu da (Org.). Identidade e diferença: a perspectiva dos estudos culturais. Petrópolis: Vozes, 2007, p. 103-133.

NOBRE, Edianne dos Santos. O teatro de Deus: a construção do espaço sagrado de Juazeiro a partir de narrativas femininas (Ceará, 1889-1898). 2010. 196 f. Dissertação (Mestrado em História e Espaços) - Universidade Federal do Rio Grande do Norte, Natal, 2010.

OLIVEIRA, Amália Xavier de. O Padre Cícero que eu conheci: verdadeira história de Juazeiro do Norte. Recife: FUNDAJ, Editora Massangana, 1989.

SILVA, Tomaz Tadeu da (Org.). Identidade e diferença: a perspectiva dos estudos culturais. Petrópolis: Vozes, 2007, p. 73-102.

SPIVAK, Gayatri Chakravorty. Pode o subalterno falar?Belo Horizonte: UFMG, 2010.

WOODWARD, Kaathryn. Identidade e diferença: uma introdução teórica e conceitual. In: SILVA, Tomaz Tadeu da (Org.). Identidade e diferença: a perspectiva dos estudos culturais. Petrópolis: Vozes, 2007, p. 7-72.

\section{a) Jornais}

Periódico: O Rebate (Juazeiro do Norte/CE)

Arquivo: Acervo digital do pesquisador Renato Casimiro (Juazeiro do Norte/CE)

ARDENTE Anhelo. O Rebate, Joaseiro, p. 1, 10 jul. 1910.

JOASEIRO. O Rebate, Joaseiro, p. 1, 29 maio 1910.

INFAMES e covardes. O Rebate, Joaseiro, p. 1, 12 jun. 1910.

PROTESTO. O Rebate, Joaseiro, p.3, 08 jan. 1911.

Periódico: O Correio do Cariri (Crato/CE)

Arquivo: Biblioteca Instituto Cultura do Cariri (Crato/CE)

CORREIO DO CARIRY. Correio do Cariry, cidade do Crato, 11 dez. 1910, p. 2.

JUAZEIRO dagua abaixo ou combate ao embuste. Correio do Cariry, cidade do Crato, 01 p. 1, jan. 1911. 
Os MILAGRES do Joaseiro. Correio do Cariry, cidade do Crato, p. 1, 06 nov. 1910.

NOVA Sodomma. Correio do Cariry, cidade do Crato, p. 1, 02 fev. 1911. 